\title{
Identification of Lonepinella sp. in Koala Bite Wound Infections, Queensland, Australia
}

\author{
Holly Angela Sinclair, Paul Chapman, \\ Lida Omaleki, Haakon Bergh, Conny Turni, \\ Patrick Blackall, Lindsey Papacostas, \\ Phillip Braslins, David Sowden, Graeme R. Nimmo
}

We report 3 cases of koala bite wound infection with Lonepinella koalarum-like bacteria requiring antimicrobial and surgical management. The pathogens could not be identified by standard tests. Phylogenetic analysis of $16 \mathrm{~S}$ rRNA and housekeeping genes identified the genus. Clinicians should isolate bacteria and determine antimicrobial susceptibilities when managing these infections.

$L$ onepinella koalarum, a species present in koala (Phascolarctos cinereus) feces, is a gram-negative bacterium that can degrade tannin protein complexes (1). This bacterium is the only species of the genus Lonepinella, a member of the family Pasteurellaceae. L. koalarum-related strains have been identified in koala gingiva (2). We report 3 cases of human wound infection involving Lonepinella-like organisms occurring after koala bites in Queensland, Australia.

\section{The Study}

In 2014, case-patient 1, a 69-year-old female wildlife worker from the Sunshine Coast region of Queensland, Australia, sought treatment for left wrist puncture wounds and a 2-cm laceration to the dorsum of her left hand after a koala bite. The wound was cleaned, and oral amoxicillin/clavulanic acid was administered. Increased erythema and edema developed after 48 hours. Surgical debridement was required, and intravenous piperacillin/tazobactam was given for 6 days, followed by oral trimethoprim and sulfamethoxazole; full recovery was achieved. A Gram stain revealed gram-positive and -negative organisms. After 48

Author affiliations: Pathology Queensland, Herston, Queensland, Australia (H.A. Sinclair, H. Bergh, G.R. Nimmo); Caboolture Hospital, Caboolture, Queensland, Australia (P. Chapman); Queensland Institute of Medical Research Berghofer, Herston (P. Chapman); The University of Queensland, Brisbane,

Queensland, Australia (L. Omaleki, C. Turni, P. Blackall);

Sunshine Coast University Hospital, Birtinya, Queensland,

Australia (L. Papacostas, D. Sowden); University of New England,

Armidale, New South Wales, Australia (P. Braslins); Griffith

University, Gold Coast, Queensland, Australia (G.R. Nimmo)

DOI: https://doi.org/10.3201/eid2501.171359 hours of culturing, we identified Staphylococcus sciuri and 2 gram-negative coccobacilli (MS14434 and MS14435).

After this case, we reviewed records and found a similar previous incident. In 2012, case-patient 2, a 62-year-old male wildlife worker from Toowoomba, Queensland, Australia, went to a general practitioner for treatment of a koala crush-bite injury to the thumb. After increased pain, swelling, fever, and malaise developed, he sought hospital care. He had an open wound (2-mm long, 5-8-mm wide, 20-mm deep) with purulent discharge. Surgical debridement was required, and intravenous ticarcillin/clavulanic acid was administered for 4 days, followed by oral amoxicillin/clavulanic acid for 7 days; clinical improvement occurred. We cultured specimens obtained during the operation and found Fusobacterium nucleatum, Staphylococcus aureus, and an unidentifiable gram-negative bacillus (MS14436).

In 2015, case-patient 3, a 66-year-old woman from Brisbane, Queensland, Australia, sought hospital treatment for a koala bite wound on her right hand. Surgical debridement and washout revealed pus within the thenar muscle compartment and metacarpophalangeal joint. Intravenous piperacillin/tazobactam was given, and the patient's condition improved. We cultured swabs of specimens acquired before and during surgery and isolated an unidentified gram-negative bacillus (MS14437).

We cultured all isolates on chocolate agar in $5 \% \mathrm{CO}_{2}$ for $48 \mathrm{~h}$ and recorded growth in different culture conditions (Table 1). We performed biochemical reactions, sugar utilization, and cultures using in-house methods and commercial identification products API 20NE Microbial Identification Kit (bioMérieux, https://www.biomerieux. com), RapID NH System (Remel, http://www.remel.com/ Clinical/Microbiology.aspx), RapID ANA II System (Remel), and VITEK 2 GN and NH ID cards (bioMérieux). We performed matrix-assisted laser desorption/ionization timeof-flight mass spectrometry using the VITEK MS IVD database (bioMérieux) and performed antimicrobial susceptibility tests per the European Committee on Antimicrobial Susceptibility Testing (EUCAST) guidelines (http://www. eucast.org/clinical_breakpoints) for Pasteurella multocida (3). We used Etest (bioMérieux) to determine MICs.

We performed DNA amplification and sequencing of 16S rRNA (4), rpoB (5), recN (6), and infB (7) genes as previously published and deposited sequences in GenBank (Appendix Table 3, https://wwwnc.cdc.gov/EID/ article/25/1/17-1359-App1.pdf). We used Geneious 10.0.6 
Table 1. Phenotypic characteristics of 4 clinical isolates obtained from koala bite wound infections, Queensland, Australia, and Lonepinella koalarum ACM 3666

\begin{tabular}{|c|c|c|c|c|c|}
\hline Growth characteristic or condition & MS14434 & MS14435 & MS14436 & MS14437 & ACM 3666 \\
\hline \multicolumn{6}{|l|}{ Growth requirement } \\
\hline$X$ factor & - & - & - & - & - \\
\hline $\mathrm{V}$ factor & - & - & - & - & - \\
\hline \multicolumn{6}{|l|}{ Biochemical reaction } \\
\hline Acetoin, Voges-Proskauer test & - & + & + & - & + \\
\hline Arginine arylamidase & + & - & - & + & - \\
\hline$\beta$-galactosidase & - & - & - & + & - \\
\hline$\beta$-glucosidase & - & + & + & + & + \\
\hline$\beta$-xylosidase & + & - & - & - & + \\
\hline Catalase & - & - & - & - & - \\
\hline $\mathrm{H}_{2} \mathrm{~S}$ & - & - & - & - & - \\
\hline Indole & - & - & - & - & - \\
\hline Leucine arylamidase & + & + & + & + & + \\
\hline Ornithine decarboxylase & - & - & - & - & - \\
\hline Oxidase & $+^{*}$ & $+^{*}$ & $+^{*}$ & $+^{*}$ & $+^{*}$ \\
\hline Phenylalanine arylaminidase & + & + & + & - & + \\
\hline Urease & - & - & - & - & - \\
\hline Courmarate & - & + & - & + & - \\
\hline Maltotriose & + & + & + & + & + \\
\hline $\mathrm{N}$-acetyl-D-glucosamine & + & + & + & - & + \\
\hline Phenylphosphonate & + & - & - & - & + \\
\hline Phosphatase & + & + & + & + & + \\
\hline Nitrate reduction & - & - & - & - & + \\
\hline Hydrolyzed esculin & - & + & + & + & + \\
\hline \multicolumn{6}{|l|}{ Sugar utilization } \\
\hline Glucose & + & + & + & + & + \\
\hline Sucrose & + & - & - & + & + \\
\hline Lactose & - & - & - & - & - \\
\hline Maltose & - & - & - & - & + \\
\hline Mannose & + & + & + & + & + \\
\hline Xylose & - & - & - & - & $+^{*}$ \\
\hline Mannitol & - & - & - & - & - \\
\hline Malate & + & + & + & + & + \\
\hline D-cellobiose & - & - & - & + & + \\
\hline \multicolumn{6}{|l|}{ Media type } \\
\hline Horse blood agar & + & + & + & + & + \\
\hline Chocolate agar & + & + & + & + & + \\
\hline Bacitracin agar & + & + & + & + & + \\
\hline Brain Heart yeast & + & + & + & + & + \\
\hline MacConkey with crystal violet & - & - & - & - & - \\
\hline Hemolysis on horse blood agar & - & - & - & - & - \\
\hline \multicolumn{6}{|c|}{ Temperature and atmospheric conditions } \\
\hline Room temperature & + & + & + & + & + \\
\hline $28^{\circ} \mathrm{C}$ Aerobic & + & + & + & + & + \\
\hline $35^{\circ} \mathrm{C}$ Aerobic & + & + & + & + & + \\
\hline $35^{\circ} \mathrm{C}$ in $5 \% \mathrm{CO}_{2}$ & + & + & + & + & + \\
\hline $35^{\circ} \mathrm{C}$ Microaerophilic & + & + & + & + & + \\
\hline $35^{\circ} \mathrm{C}$ Anaerobic & + & + & + & + & + \\
\hline $42^{\circ} \mathrm{C}$ Aerobic & - & - & - & + & - \\
\hline
\end{tabular}

(https://www.geneious.com) to align and analyze sequences. We performed a neighbor-joining analysis of 16S rRNA sequences by using Jukes-Cantor corrections and calculated bootstrap support in MEGA version 6 (https://www. megasoftware.net). We calculated the similarity matrix using MUSCLE (https://www.ebi.ac.uk/Tools/msa/muscle) and predicted genome relatedness using a previously published formula using the $\operatorname{recN}$ gene $(8,9)$.

The colony morphology of the 2 isolates from case-patient 1 were distinctly different from each other; MS14434 was morphologically similar to MS14437, and MS14435 was similar to MS14436. Optimal colony growth was seen on chocolate agar with $5 \% \mathrm{CO}_{2}$ and under microaerophilic conditions (Table 1). Results from commercial identification systems were mostly inconsistent (Appendix Table 1); note that $L$. koalarum is not included within the commercial databases used.

The MICs of all the antimicrobial drugs tested for MS14434 and MS14435 were low (Appendix Table 2); MICs for MS14436 and MS14437 were higher. MS14436 and MS14437 were resistant to benzylpenicillin when applying P. multocida breakpoints (3). 
Table 2. Similarity matrix of $16 \mathrm{~S}$ rRNA, $r p o B$, infB, and $r e c N$ gene sequences of 4 clinical isolates obtained from koala bite wound infections, Queensland, Australia, and Lonepinella koalarum ACM 3666*

\begin{tabular}{lccccc}
\hline $\begin{array}{l}\text { Gene and } \\
\text { isolate }\end{array}$ & MS14434 & MS14435 & MS14436 & MS14437 & 3666 \\
\hline $\begin{array}{l}\text { 16SrRNA } \\
\text { MS14434 }\end{array}$ & 100 & & & & \\
MS14435 & 96.52 & 100 & & & \\
MS14436 & 96.50 & 98.45 & 100 & & \\
MS14437 & 97.48 & 98.16 & 98.00 & 100 & \\
ACM 3666 & 94.82 & 95.26 & 96.00 & 95.45 & 100 \\
\hline rpoB & & & & & \\
MS14434 & 100 & & & & \\
MS14435 & 95.77 & 100 & & & \\
MS14436 & 96.54 & 97.69 & 100 & & \\
MS14437 & 95.96 & 99.42 & 97.88 & 100 & \\
ACM 3666 & 95.96 & 95.96 & 95.00 & 96.35 & 100 \\
\hline infB & & & & & \\
MS14434 & 100 & & & & \\
MS14435 & 84.34 & 100 & & & \\
MS14436 & 83.89 & 98.66 & 100 & & \\
MS14437 & 84.34 & 96.20 & 95.75 & 100 & \\
ACM 3666 & 99.78 & 84.12 & 83.67 & 84.12 & 100 \\
\hline recN & \multicolumn{5}{c}{100} \\
MS14434 & 100 & & & & \\
MS14435 & 83.90 & 100 & & & \\
MS14436 & 84.13 & 99.06 & 100 & & \\
MS14437 & 83.97 & 99.53 & 99.37 & 100 & \\
ACM 3666 & 97.17 & 83.97 & 84.21 & 84.05 & 100 \\
\hline${ }^{*}$ Values are percentage identity. & & & & \\
\hline
\end{tabular}

We compared 16S rRNA and $r p o B$ gene sequences from our isolates with those available in public databases, including GenBank, but confident organism identification was not possible. The 16S rRNA phylogenetic analysis clustered all 4 isolates distantly from L. koalarum (ACM 3666), albeit within the same group (Figure).

For the rpoB gene sequence, an identity of $85 \%-88 \%$ for genera and $95 \%$ for species has been suggested for Pasteurellaceae $(2,10,11)$. All isolates of this study had an identity of $>95 \%$ for the rpoB gene of ACM 3666 (Table 2 ), indicating a close genetic relationship with $L$. koalarum. A minimum level of $83 \%-85 \%$ identity of the partial infB gene has been shown between members of the Pasteurellaceae family at the genus level (12). The partial inf $B$ gene sequence of MS14434 had a high similarity $(99.78 \%)$ to the corresponding sequence in ACM 3666, and the partial $\inf B$ genes of the other 3 isolates are at the lower limit of the $83 \%-85 \%$ threshold. These 3 isolates also shared $<85 \%$ similarity with the recN gene of ACM 3666 and $>99 \%$ similarity with the $r e c N$ gene of each other. The $r e c N$ gene of MS14434 had $97.17 \%$ similarity with that of ACM 3666. Using the recN similarity index (8), we are $95 \%$ confident that these 3 isolates are a species other than L. koalarum within the genus Lonepinella, and MS14434 is most likely L. koalarum.

Each case manifested with purulent skin and soft tissue infection requiring surgical washout and debridement, similar to infections linked to Pasteurella in dog and cat bite wounds (13). MICs of amoxicillin and clavulanic acid, third-generation cephalosporins, and ciprofloxacin were low for all isolates. MIC determination should be sought because 2 isolates were nonsusceptible to benzylpenicillin on the basis of $P$. multocida interpretation criteria (3). For

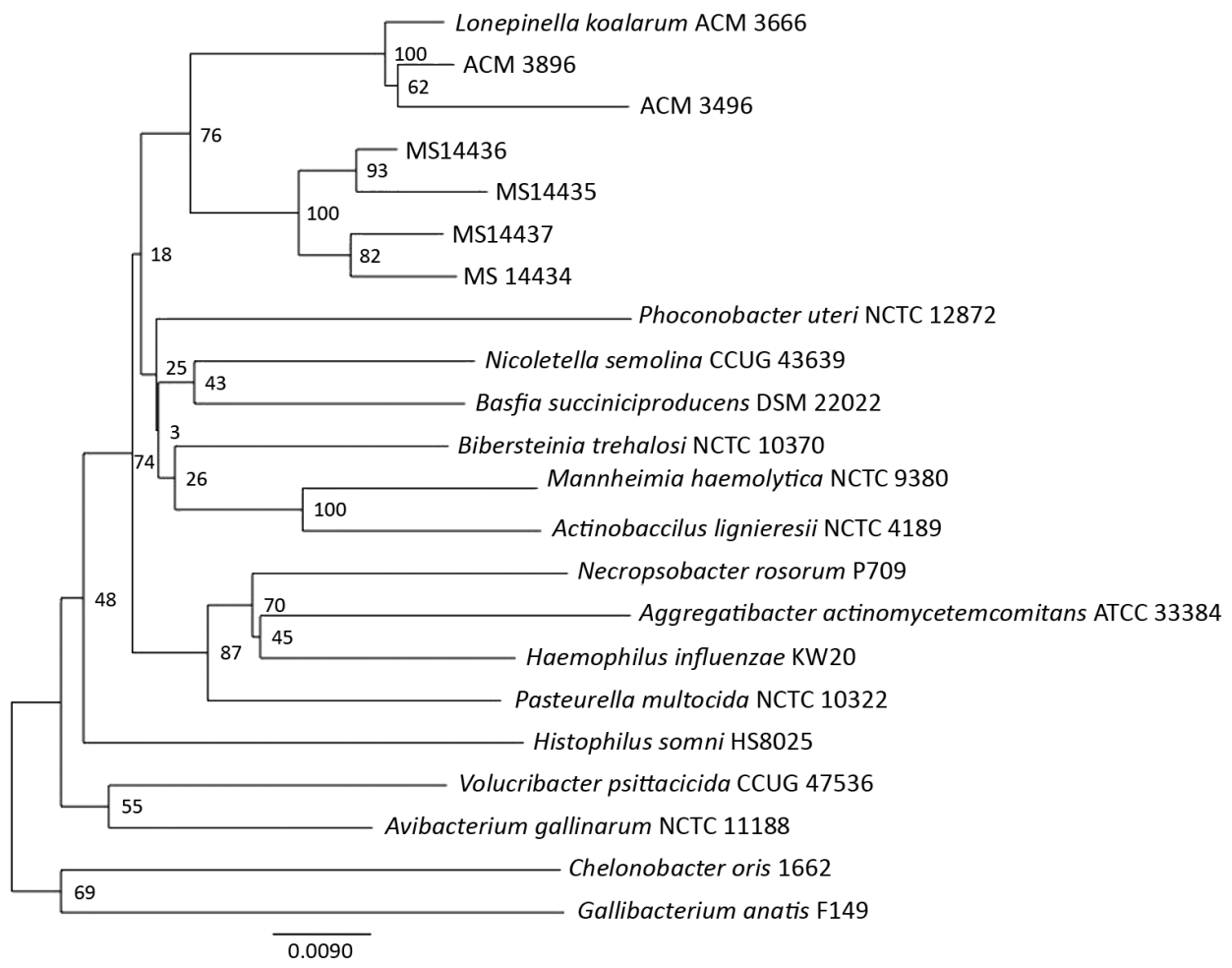

Figure. Neighbor-joining phylogenetic analysis of $16 \mathrm{~S}$ rRNA gene sequences of 4 clinical isolates obtained from koala bite wound infections in 3 persons (MS14434-7), Queensland, Australia, 3 Lonepinella koalarum ACM isolates, and members of the Pasteurellaceae family. Scale bar represents nucleotide substitutions per site. 
resolution of infection, surgical drainage might be required in addition to antimicrobial drug therapy.

In the original study of L. koalarum (1), 7 isolates were grouped into 4 biovars (a-d), and 16S rRNA sequencing demonstrated high similarity $(97.6 \%-99.8 \%)$. A threshold of $93 \%-94 \%$ identity between $16 \mathrm{~S}$ rRNA gene sequences has been described for differentiating members of Pasteurellaceae at the genus level (5) and $>97 \%$ at the species level (10). Although all 4 isolates in our study showed $>93 \%$ similarity to L. koalarum ACM 3666 in their 16S rRNA genes, none of them reached $97 \%$ similarity. Both infB and $r e c N$ gene sequences indicated a close relationship between MS14434 and ACM 3666; however, 16S rRNA and rpoB gene sequences showed the same level of similarity between all 4 isolates and the reference L. koalarum strain. This disagreement between genes could be a result of lateral gene transfer; lateral gene transfer of housekeeping genes has been described as a reason for incongruence between $16 \mathrm{~S}$ rRNA and housekeeping gene phylogeny (14).

\section{Conclusions}

Clinical and microbiological suspicion is required when assessing bacteria from koala bite wounds. Phenotypic and biochemical colony characteristics are often unreliable at assigning isolates to a genus and species within the Pasteurellaceae family, and identification with commercial kits is not always possible. Pasteurellaceae spp., including L. koalarum, can be identified by using matrix-assisted laser desorption/ionization time-of-flight mass spectrometry with updated spectra (15). Clinical laboratory identification methods involve sequencing the 16S rRNA gene and searching nucleotide databases. As seen in this investigation, this approach can be inconclusive, and phylogenetic analysis of sequences including housekeeping genes might be required.

In summary, Lonepinella infections acquired after koala bites can cause clinically significant human skin and soft tissue disease. In this report, we identified possibly novel Lonepinella-like organisms with a combination of genetic analyses.

\section{Acknowledgments}

We thank Scott A. Beatson and Leah Roberts for their scientific support.

\section{About the Author}

Dr. Sinclair is an advanced trainee in microbiology and infectious diseases with the Royal College of Pathologists Australasia and Royal Australasian College of Physicians. Her primary research interests include bacteriology, Aeromonas identification and infection, antimicrobial resistance, and phylogenetics.

\section{References}

1. Osawa R, Rainey F, Fujisawa T, Lang E, Busse HJ, Walsh TP, Stackebrandt E. Lonepinella koalarum gen. nov., sp. nov., a new tannin-protein complex degrading bacterium. Syst Appl Microbiol. 1995; 18:368-73.

2. Hansen MJ, Bertelsen MF, Kelly A, Bojesen AM. Occurrence of Pasteurellaceae Bacteria in the Oral Cavity of Selected Marsupial Species. J Zoo Wildl Med. 2017;48:1215-8. http://dx.doi.org/10.1638/2017-0071.1

3. European Committee on Antimicrobial Susceptibility Testing. Breakpoint tables for interpretation of MICs and zone diameters. Version 5.0. 2015 Jan 1 [cited 2017 Aug 15]. http://www.eucast.org/ mic_distributions_and_ecoffs/

4. Nikkari S, Lopez FA, Lepp PW, Cieslak PR, Ladd-Wilson S, Passaro D, et al. Broad-range bacterial detection and the analysis of unexplained death and critical illness. Emerg Infect Dis. 2002;8:188-94. http://dx.doi.org/10.3201/eid0802.010150

5. Korczak B, Christensen H, Emler S, Frey J, Kuhnert P. Phylogeny of the family Pasteurellaceae based on $r p o B$ sequences. Int J Syst Evol Microbiol. 2004;54:1393-9. http://dx.doi.org/10.1099/ijs.0.03043-0

6. Mullins MA, Register KB, Brunelle BW, Aragon V, Galofré-Mila N, Bayles DO, et al. A curated public database for multilocus sequence typing (MLST) and analysis of Haemophilus parasuis based on an optimized typing scheme. Vet Microbiol. 2013;162:899-906. http://dx.doi.org/10.1016/j.vetmic.2012.11.019

7. Omaleki L, Barber SR, Allen JL, Browning GF. Mannheimia species associated with ovine mastitis. J Clin Microbiol. 2010;48:3419-22. http://dx.doi.org/10.1128/JCM.01145-10

8. Zeigler DR. Gene sequences useful for predicting relatedness of whole genomes in bacteria. Int J Syst Evol Microbiol. 2003; 53:1893-900. http://dx.doi.org/10.1099/ijs.0.02713-0

9. Kuhnert P, Korczak BM. Prediction of whole-genome DNA-DNA similarity, determination of $\mathrm{G}+\mathrm{C}$ content and phylogenetic analysis within the family Pasteurellaceae by multilocus sequence analysis (MLSA). Microbiology. 2006;152:2537-48. http://dx.doi.org/ 10.1099/mic.0.28991-0

10. Christensen H, Kuhnert P, Busse HJ, Frederiksen WC, Bisgaard M. Proposed minimal standards for the description of genera, species and subspecies of the Pasteurellaceae. Int J Syst Evol Microbiol. 2007;57:166-78. http://dx.doi.org/10.1099/ijs.0.64838-0

11. Bisgaard M, Nørskov-Lauritsen N, de Wit SJ, Hess C, Christensen H. Multilocus sequence phylogenetic analysis of Avibacterium. Microbiology. 2012;158:993-1004. http://dx.doi.org/10.1099/mic.0.054429-0

12. Nicklas W, Bisgaard M, Aalbæk B, Kuhnert P, Christensen H. Reclassification of Actinobacillus muris as Muribacter muris gen. nov., comb. nov. Int J Syst Evol Microbiol. 2015;65:3344-51. http://dx.doi.org/10.1099/ijsem.0.000417

13. Dendle C, Looke D. Review article: Animal bites: an update for management with a focus on infections. Emerg Med Australas. 2008;20:458-67.

14. Christensen H, Kuhnert P, Olsen JE, Bisgaard M. Comparative phylogenies of the housekeeping genes atpD, infB and $r p o B$ and the 16S rRNA gene within the Pasteurellaceae. Int J Syst Evol Microbiol. 2004;54:1601-9. http://dx.doi.org/10.1099/ijs.0.03018-0

15. Kuhnert P, Bisgaard M, Korczak BM, Schwendener S, Christensen H, Frey J. Identification of animal Pasteurellaceae by MALDITOF mass spectrometry. J Microbiol Methods. 2012;89:1-7. http://dx.doi.org/10.1016/j.mimet.2012.02.001

Address for correspondence: Holly A. Sinclair, Pathology Queensland, Department of Microbiology, Level 5, Block 7, Royal Brisbane and Women's Hospital Complex, Herston, QLD 4029, Australia; email: holly.sinclair@health.qld.gov.au or sinclair_holly@hotmail.com 